\title{
Reseña. Sergio Eduardo Carrera Quezada. Sementeras de papel: la regularización de la propiedad rural en la Huasteca serrana, 1550-1720. México: Colegio de México, Centro de Investigaciones y Estudios Superiores en Antropología Social, 2018.386p.
}

\author{
Jhon Florián Guzmán \\ Estudiante del Doctorado en Historia del Centro de Estudios Históricos- \\ El Colegio Michoacán, México \\ jhfloriang@colmich.edu.mx
}

Sugerencia de citación: Florián Guzmán, J. (2019). Reseña. Sergio Eduardo Carrera Quezada. Sementeras de papel: la regularización de la propiedad rural en la Huasteca serrana, 1550-1720. México: Colegio de México, Centro de Investigaciones y Estudios

Superiores en Antropología Social, 2018. 386p. tiempo\&economía, 6(2), 107-110 doi: http://dx.doi.org/10.21789/24222704.1444

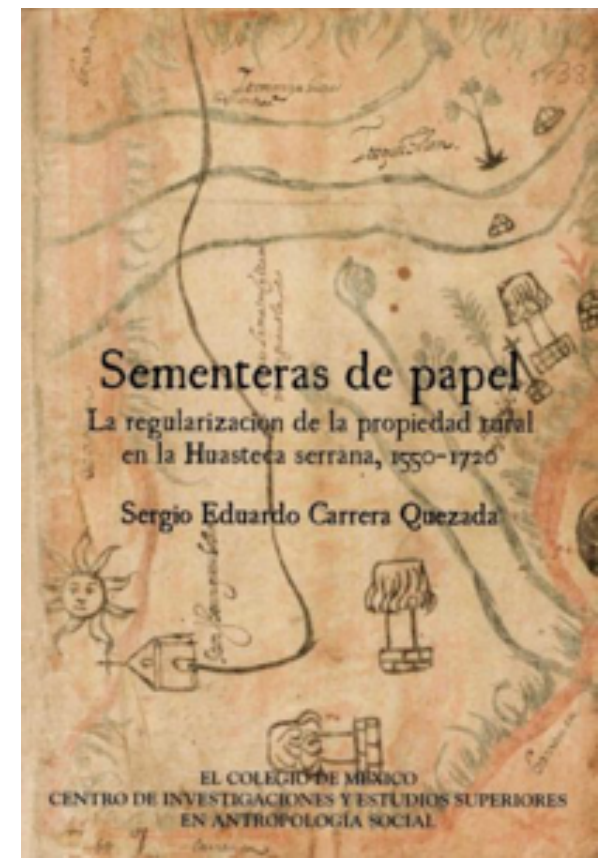


Este libro, nutrido de la tradición de Carlos Sempat Assadourian, tiene la virtud de lograr una original y bien documentada síntesis de la política agraria novohispana de los siglos XVI, XVII y xVIII. Gran parte del cuerpo de esta investigación se basa en la tesis doctoral de Sergio Eduardo Carrera Quezada: "Conformación de la territorialidad española y de los pueblos de indios en la Sierra Huasteca" (UNAM, 2013), ganadora del xv Premio Banamex Atanasio G. Saravia de Historia Regional Mexicana 2012-2013 y el Premio Francisco Javier Clavijero de Historia y Etnohistoria en 2014.

Con este trabajo, el autor buscó exponer las reconfiguraciones espaciales por las que atravesaron los pueblos indios que habitaban la zona serrana de la Huasteca durante el siglo xv al XVIII. Entre los diferentes factores que incidieron en la distribución geográfica de estos pueblos, el autor destaca al menos cuatro: las directrices virreinales de entrega de títulos, los ajustes provocados por las congregaciones, la consolidación de las haciendas y los resultados de las composiciones de tierras y aguas.

Sobre la política agraria colonial se ha producido una importante historiografía que se ha concentrado en las bases jurídicas del dominio de la Corona española de Indias, y los mecanismos que permitieron la apropiación de tierras. Sin embargo, son muy pocas las obras que han prestado atención a las diligencias de composiciones, en parte porque la territorialidad indígena fue estudiada a la luz de estudios de textos nativos. Carrera exalta las composiciones como un recurso ante la escasez de otros materiales.

Dichos documentos reúnen información valiosa sobre el número de haciendas y ranchos, los nombres de sus dueños, los pueblos con sus bienes de comunidades, las tierras corporativas y patrimoniales, los títulos y escrituras de posesión, el registro de los linderos entre localidades y propiedades particulares, superficies y extensiones de terrenos, las cantidades liquidadas a la Real Hacienda, entre otros datos importantes para el estudio de las propiedades rurales, el ordenamiento territorial y de los componentes del paisaje (22)

Las composiciones hacen parte de la política de tierras de la Corona por regir sobre el acceso y ocupación del suelo. Desde 1590 se buscó incrementar las arcas reales a través del cobro del arbitrio de los bienes realengos, por lo que a partir de estas disposiciones se abrieron nuevas categorías de propiedad que dieron vida a los distintos accesos, ocupaciones y beneficios del uso del suelo. La composición en este sentido, convirtió una ocupación de hecho en una situación de derecho, a cambio de una contribución monetaria. Estas primeras composiciones se realizaron con el propósito de legalizar las transacciones, mientras que las llevadas a cabo posteriormente buscaron expandir las haciendas. Al respecto, los procesos son amplios, en algunos casos estas composiciones tomaron tierras de los pueblos de indios, en otros fueron medidas que protegieron las propiedades de los naturales. En particular, en la sierra Huasteca, Carrera sostiene que las composiciones no arrebataron tierras a los naturales, aunque sí los obligaron a pagar por el derecho de titulación para regularizarlos.

Una de las cualidades de esta investigación es la capacidad para demostrar la rapidez con que los naturales emplearon los mecanismos jurídicos para negociar su condición de vasallos del rey. A partir de las visitas y congregaciones se puede constatar la manera como los pueblos de la serranía de Metztitlán y Huayacocotla recurrieron a diferentes recursos para que parte de sus patrones de tenencia de la tierra adaptaran, y en parte sobrevivieran, a la creación de las congregaciones. En otras palabras, estas poblaciones de indios apropiaron con gran versa- 
tilidad los recursos jurídicos de los españoles para dar continuidad a su organización política, cultural y económica. La personalidad jurídica sirvió para defender tierras y mantener cierta estabilidad, al menos hasta que nuevas composiciones de los bienes comunales fragmentaran y descentralizaran el gobierno entre 1692 y 1720.

El otro actor importante fue el colono. La concesión de tierras a españoles dependió de las recompensas a la conquista y sometimiento, las fundaciones de villas de españoles, la crisis demográfica y la reubicación de los pueblos en congregaciones. En todas, quedaban disponibles nuevas áreas para ser ocupadas, en particular luego del último tercio del siglo XVI, cuando el altiplano central ya evidenciaba agotamiento de sus tierras para cultivo y levante y engorde de ganado vacuno. En este punto, Carrera establece una cronología de las mercedes y otros títulos de propiedad entre el siglo xVI y XVII, con la que expone con bastante claridad los distintos mecanismos de los colonos para hacerse con la tierra y acapararla a través de las compraventas.

La distribución de tierras entre colonos, sin perjuicio de los bienes y heredades de los naturales, se formuló con las reales cédulas de 1591, aunque sólo se manifestaron títulos un siglo después. El cobro de las composiciones ingresado en la Real Caja de México fue de poca importancia, con lo que se demuestra que los objetivos de regularización agraria no pudieron alcanzarse sino hasta el siglo xVII y xVIII. A los ojos de la Corona, los virreyes fueron muy indulgentes en materia agraria. Las negociaciones a favor de la regularización de posesiones ilegítimas se hizo en detrimento de los bienes de los indios y los derechos del Rey sobre las tierras realengas, por lo que a finales del siglo xvıl la Corona tomó la decisión de reformular la política agraria, tanto para corregir los privilegios excesivos entregados a los colonos, como para dar alivio a la presión tributaria.

No obstante, este cuestionado proceso de composiciones de tierras y aguas de 1643 a 1674, no alimentó la desmesurada expansión de la hacienda por la vía legal que la historiografía mexicana reportó para el siglo xVII y XVIII. La estructura agraria de la Huasteca estuvo signada por fuertes procesos de desmembramiento. Cabrera reconstruyó a partir de autos, diligencias, mercedes y el Libro de Administraciones y sus Cuentas (1660-1675) que la composición general de 1643 y las manifestaciones de títulos de 1675 convirtieron a los dueños de haciendas en legítimos propietarios, pero esta regularización no detuvo la atomización a la que fueron expuestas tras la muerte de sus dueños o el deseo de rematarlas por parte de los herederos. En lugar de una expansión de las haciendas, el autor encontró en la Huasteca una tendencia a la atomización. Parte de los ocupantes de estas haciendas, adquirían propiedades de menor tamaño y valor, aunque sin la titularidad legítima de las tierras.

Ante el fracaso del cobro de las composiciones y el fallido ordenamiento territorial, la Corona creó en 1692 la Superintendencia del Beneficio y Composición de Tierras. Su propósito era lanzar una política agraria de mayor envergadura, para lo cual subordinó a los Juzgados Privativos de Tierras, y exigió a todos los estamentos sociales información sobre el tamaño y estado de las tierras. Los rastros documentales de esta política fueron estudiados y articulados en detalle por el autor, y resumidos en un catastro de Huayacocotla y Yahualica entre 1696 y 1720.

Al seguirle el rastro a las disposiciones de los jueces, Sergio Eduardo Carrera Quezada no sólo logró una auténtica radiografía de la estructura agraria de la época, sino que además rescató las composiciones como una valiosa fuente para comprender las dinámicas espaciales y 
ambientales de los colonos y los pueblos de indios. En el caso de la Huasteca, Carrera encontró una doble dinámica. Por un lado, la regularización permitió la negociación y legalización de los predios de los pueblos de indios en favor de una mayor certeza jurídica; por otro lado, se abrió la ventana a posteriores separaciones de pueblos y a la formación de nuevas repúblicas de naturales. Lo anterior fue un proceso finamente documentado que invita, a través de la claridad y síntesis del autor, a ser replicado en otras regiones y periodos de la colonia. 